\title{
O médico de família e o Covid-19
}

Paulo Santos, Tiago Maricoto, Rui Nogueira, Alberto Hespanhol

We cannot solve our problems with the same level of thinking that created them.

Albert Einstein

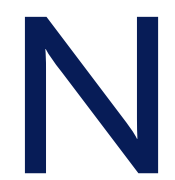

o dia 31 de dezembro de 2019 as autoridades chinesas reportaram à Organização Mundial da Saúde (OMS) a existência de um surto de pneumonia de etiologia desconhecida na cidade de Wuhan, província de Hubei, na China. Um novo vírus da família dos coronavírus, entretanto classificado como SARS-Cov-2, foi identificado como a causa da doença chamada Covid-19. Trata-se de uma doença com uma amplitude de apresentação clínica entre um vulgar resfriado e uma pneumonia grave com falência multiorgânica, sépsis e eventualmente morte.

Um mês depois, em 31 de janeiro de 2020, a China reportava 9.714 casos e 213 mortos, representando $99,9 \%$ dos casos no mundo inteiro, onde não se registava mais nenhum óbito.

Já havia experiência anterior com vírus desta família. Na China, em 2002-2003, o vírus SARS-CoV passou do morcego aos humanos e provocou 8.096 casos de síndroma de stress respiratório agudo (SARS) e vitimou 774 doentes, sem novos casos notificados desde 2013. Na Arábia Saudita, desde 2012, o vírus MERS-CoV, uma zoonose com transmissão a partir dos dromedários da Península Arábica, provocou 2.519 casos e 866 mortes, mantendo-se ainda ativo.

Números impressionantes pela taxa de letalidade específica, mas limitados na sua expressão clínica, seja por serem limitados no tempo (SARS-CoV), seja por serem limitados na distribuição geográfica (MERS-CoV).

Nesta altura, o SARS-CoV-2 não era motivo de preocupação excessiva para o resto do mundo. A maior parte dos casos prevalentes situava-se em países à volta da China e os casos mais distantes apresentavam uma ligação direta à província de Hubei e à cidade de Wuhan.

*Equipa editorial da RPMGF.
Os primeiros casos na Europa foram notificados em 25/01, na Rússia em 01/02, nos Estados Unidos em 21/01 e no Canada em 26/01. A situação não se alterou significativamente nas duas primeiras semanas de fevereiro, mesmo depois de ter sido registado o primeiro óbito no espaço europeu em 15/02 em França, numa altura em que os dados provenientes da China pareciam já ter ultrapassado o pico, mostrando uma descida no número diário de novos casos.

Uma vez mais a Europa tinha resistido a uma epidemia.

Mas, no dia 22 de fevereiro, a evolução dos novos casos no Continente Europeu começa a apresentar um crescimento exponencial. Em 4 de março o número de novos casos na Europa ultrapassa os da China e quatro dias depois ultrapassa os do resto do mundo (incluindo a China).

Em 11 de março, a OMS declara que o Covid-19 é uma pandemia, que significa que a infeção se alastrou a todo o mundo, ou a uma parte significativa, e que atinge um grande número de pessoas. ${ }^{1}$

A Europa está perante uma realidade que não se previa e não se antecipou. O modelo cultural e social europeu abriu um espaço de mais de 4 milhões de $\mathrm{km}^{2}$, onde vivem 446 milhões de pessoas. Nesta Europa, o que acontece hoje em Milão reflete-se em Lisboa ou em Helsínquia no espaço de breves horas. A China é um país com 1,4 biliões de pessoas. A província de Hubei tem $59 \mathrm{mi}-$ lhões de habitantes, equivalente a Itália com 60 milhões, e a cidade de Wuhan tem 19 milhões de habitantes, o mesmo que o conjunto das províncias da Lombardia, Emília-Romanha e Veneto, as três mais afetadas pelo SARS-CoV-2. Mas a realidade é significativamente diferente nos processos de mobilidade e de vivência social.

Em Portugal o primeiro caso foi notificado em $2 \mathrm{de}$ março e o primeiro óbito ocorreu em 16 de março. Escrevemos este texto no dia em que faz um mês sobre este primeiro caso. No dia 2 de abril temos oficialmente 9.034 casos confirmados, 209 óbitos e 240 doentes internados em unidades de cuidados intensivos. 
No início, a estratégia de combate à epidemia foi estabelecida com base na resposta hospitalar de internamento e isolamento dos casos detetados, sendo necessário estabelecer a ligação epidemiológica para a presunção de caso: um doente com sintomas respiratórios (febre, tosse e dificuldade respiratória) só poderia ser considerado suspeito se apresentasse um contacto direto ou indireto com caso confirmado ou provável de infeção por SARS-CoV-2, nos 14 dias antes do início dos sintomas (Orientação n. ${ }^{\circ}$ 002/2020 de 25/01/2020, atualizada em 10/02/2020), depois acrescentado com os casos de doença respiratória requerendo hospitalização (Orientação n. ${ }^{\circ}$ 002A/2020, de 25/01/2020, atualizada em 09/03/2020). A validação da suspeição clínica passava obrigatoriamente por um contacto com a Linha de Apoio ao Médico, entretanto criada na estrutura da Direção-Geral da Saúde. Aos cidadãos foi oferecido um rastreio telefónico na Linha SNS24. São numerosos os relatos de quem passou horas a tentar estabelecer a comunicação com os serviços para desespero tanto de médicos como de doentes.

Longe das decisões palacianas, o país percebeu que tinha de ser concreto nas ações. Os profissionais de saúde suspenderam as formações em curso ou a realizar, fecharam-se as universidades, começando pelos cursos médicos, depois as escolas básicas e secundárias, seguido de um apelo à evicção dos ajuntamentos públicos e da sua proibição completa a 18 de março na declaração do estado de emergência pelo Sr. Presidente da República.

A Direção-Geral da Saúde, no entanto, manteve a orientação até $26 / 03 / 2020$, com a entrada em vigor da Norma n. ${ }^{\circ}$ 004/2020, de 23/03/2020, que transfere finalmente a decisão clínica para a avaliação médica, que, no entanto, permanece ligada a um conjunto normativo que mais do que orientador na forma e no processo se mostra confuso e criador de entropia.

Na prática, porém, é aqui que a estrutura de base do Serviço Nacional de Saúde, que tão bem tem cuidado da saúde dos portugueses, é chamada a agir nesta epidemia: dois meses depois do primeiro caso na Europa e 24 dias após o primeiro caso em Portugal.

É expectável que a maioria dos casos de infeção por SARS-CoV-2 tenha uma evolução benigna e pouco sintomática. Numa série chinesa incluindo 72.314 doentes, $80,9 \%$ apresentaram doença ligeira, sem qualquer morte associada. Os óbitos foram todos registados entre os doentes críticos $(4,7 \%)$ com uma taxa de letalidade de $49,0 \%{ }^{2}$

Em prevenção primária interessa perceber quais os grupos de risco onde a doença pode apresentar uma maior severidade e onde naturalmente se impõe uma atitude preventiva mais rigorosa: idade superior a 60 anos e presença de comorbilidades (hipertensão arterial, doença cardiovascular, diabetes, doença oncológica e doença respiratória crónica)..$^{2-3}$ Também em prevenção primária assume particular relevância a intervenção educativa personalizada na intimidade da consulta ou gerindo, e até liderando, o fluxo informativo nas diferentes plataformas atualmente disponíveis, ${ }^{4}$ não esquecendo o papel paradigmático do médico na forma como procede perante a sua comunidade. Em prevenção secundária ter-se-á de definir claramente se o objetivo é rastrear toda a população, proceder ao diagnóstico nos casos suspeitos ou simplesmente validar a etiologia nos casos graves. Dificilmente na atual conjuntura poder-se-ia optar pela via minimalista de rastrear à porta dos cuidados intensivos e não existe evidência que justifique a opção de rastreio sistemático populacional. O diagnóstico é um direito dos doentes e no atual quadro epidemiológico não se pode deixar de realçar a importância de realizar os testes diagnósticos em todos os níveis de cuidados. Somos, como sempre, o pivot do sistema, colocados na garantia de uma visão orientada, mas global, enquadrando a pessoa que está doente no seu contexto de vida. E, neste enquadramento, é importante neste momento rever a carteira de serviços disponível e poder adiar o adiável, sem perder de vista o acompanhamento em continuidade e os objetivos de saúde que temos com os nossos doentes. E temos de estar acessíveis porque é essa a nossa missão, sobretudo neste tempo em que, na dúvida, as pessoas vão recorrer ao seu médico em busca da segurança e orientação a que estão habituadas.

O papel do médico de família será o de sempre. ${ }^{5}$ Seremos o médico generalista de cuidados personalizados, globais e em continuidade a todos os que nos procuram, independentemente da idade, género, etnia ou estado de saúde. Promoveremos uma medicina integral que conjuga os dados atuais da pessoa com o seu passado biopsicossocial, com a sua estrutura familiar e com a comunidade envolvente, nas suas características 
demográficas e socioculturais, oferecendo uma visão holística só possível neste contexto. Utilizaremos a interação única da relação médico-doente como ferramenta terapêutica no seu contexto e no seu resultado. Trabalharemos em equipa com outros profissionais, médicos e não médicos, nos diferentes níveis de assistência, compreendendo que isoladamente não conseguimos prestar os melhores cuidados à pessoa que em nós confia a sua saúde e a sua doença. Continuaremos a enquadrar o doente, não apenas como o portador de um diagnóstico, mas como uma pessoa que neste momento se encontra doente e, sem descurar o necessário tratamento que queremos baseado na melhor evidência, manter uma abertura para os aspetos de medicina preventiva, reabilitação e paliação que esta pessoa necessita.

Continuaremos a ser o primeiro ponto de contacto do cidadão com o sistema de saúde, acompanhando-o no processo e provendo pela sua saúde, curando algumas vezes, aliviando quase sempre e consolando sempre, como afirmou Hipócrates.

\section{REFERÊNCIAS BIBLIOGRÁFICAS}

1. Porta MS, editor. A dictionary of epidemiology. 6th ed. Oxford: Oxford University Press; 2014. ISBN 9780195314496

2. Novel Coronavirus Pneumonia Emergency Response Epidemiology Team. [The epidemiological characteristics of an outbreak of 2019 novel coronavirus diseases (COVID-19) in China]. Zhonghua Liu Xing Bing Xue Za Zhi. 2020;41(2):145-51.

3. Cascella M, Rajnik M, Cuomo A, Dulebohn SC, Di Napoli R. Features, evaluation and treatment coronavirus (COVID-19) [Internet]. Treasure Island (FL): StatPearls Publishing; 2020. Available from: https://www. ncbi.nlm.nih.gov/books/NBK554776/

4. Santos P, Sá L, Couto L, Hespanhol AP. Sources of information in health education: a cross-sectional study in Portuguese university students. Australas Med J. 2018;11(6):352-60.

5. Allen J, Gay B, Crebolder H, Heyrman J, Svab I, Ram P. The European definition of general practice/family medicine [Internet]. In: SemFYC, EURACT. Barcelona:WONCA; 2011. Available from: https://www.woncaeurope.org/file/520e8ed3-30b4-4a74-bc35-87286d3de5c7/Definition\%203rd\%20ed\%202011\%20with\%20revised\%20wonca\% 20tree.pdf

\section{ENDEREÇO PARA CORRESPONDÊNCIA}

E-mail: psantosdr@med.up.pt https://orcid.org/0000-0002-2362-5527 